\title{
Intoxicación por triyodotironina. Estudio clínico y farmacocinético
}

\author{
J. BOTELLA DE MAGLIA, L. COMPTE TORRERO ${ }^{1}$, A. RIVAS SÁNCHEZ ${ }^{2}$, \\ J. L. PÉREZ PASTOR ${ }^{2}$ \\ Servicios de Medicina Intensiva, ${ }^{\prime}$ Neumología $y^{2}$ Medicina Nuclear. Hospital La Fe. \\ Valencia
}

\section{RESUMEN}

A una mujer tiroidectomizada por carcinoma papilar de tiroides se le suspendió el tratamiento con L-tiroxina para realizar un estudio de extensión cinco semanas después. Para minimizar sus síntomas durante las tres primeras semanas se le prescribió tratamiento con cápsulas de $25 \mu \mathrm{g}$ de triyodotironina cada 8 horas. Nueve días después consultó por dolor abdominal, náuseas, vómitos, fiebre de $40{ }^{\circ} \mathrm{C}$, mareo y molestia torácica. Mediante inmunoanálisis quimioluminiscente se detectó una triyodotironina sérica total de $575,2 \mathrm{nmol} / 1$ a las 11 horas de la toma de la última cápsula (valor normal: 1,1-2,9 nmol/1). A lo largo de los diez días siguientes la enferma presentó delirio, agitación, taquicardia, hipertensión arterial, estreñimiento y luego diarrea, pero no arritmias ni temperatura superior a $38{ }^{\circ} \mathrm{C}$. Se realizaron 59 determinaciones de triyodotironina total para determinar la cinética de eliminación de esta hormona. Se calcula que la máxima concentración sérica tras la ingestión de la última cápsula debió ser de 794,3 nmol/l, es decir, 397 veces superior al promedio de la normalidad. La vida media de eliminación fue de 24 horas y 40 minutos. La hemoperfusión con carbón activado no tuvo impacto alguno sobre la velocidad de eliminación. La concentración de triyodotironina se normalizó a las 200 horas de la toma de la última cápsula, pero las manifestaciones clínicas tardaron tres días más en desaparecer. Los datos farmacocinéticos sugieren que la intoxicación pudo deberse a que durante nueve días la paciente tomara cápsulas con $5 \mathrm{mg}$ de triyodotironina, es decir, una dosis 200 veces mayor que la prescrita por su médico.

PALABRAS CLAVE: Triyodotironina. Intoxicación. Sobredosis. Hemoperfusión con carbón activado. Farmacocinética.
TRIIODOTHYRONINE INTOXICATION. A CLINICAL AND PHARMACOKINETIC STUDY

\section{ABSTRACT}

A woman, thyroidectomised because of a thyroid papillary carcinoma interrupted temporarily her levothyroxine intake in order to be subjected to an extension study five weeks later. To minimise her symptoms for the first three weeks, a treatment was prescribed consisting of one $25 \mu \mathrm{g}$-capsule of triiodothyronine every 8 hours. Nine days later she complained of abdominal pain, nausea, vomiting, fever of $40^{\circ} \mathrm{C}$ and chest discomfort. A serum total triiodothyronine of $575.2 \mathrm{nmol} / \mathrm{l}$ was measured by chemoluminiscent immunoassay eleven hours after the intake of the latest capsule (normal level: 1.1-2.9 nmol/l). Along the following ten days the patient suffered from delirium, agitation, tachycardia, hypertension, constipation and later diarrhoea, but neither arrythmias nor axillary temperature over 38 ${ }^{\circ} \mathrm{C}$. Fifty-nine measurements of the serum total triiodothyronine were performed in order to determine the kinetics of elimination of this drug. We estimate that the maximal serum concentration after the intake of the latest capsule could be 794.3 nmoll, i.e. 397 times higher than the mean normal value. The elimination half-life was 24 hours 40 minutes. The charcoal haemoperfusion had no impact on the velocity of elimination. The concentration of triiodothyronine became normal 200 hours after the intake of the latest capsule, but the clinical manifestations still lasted three days more. The pharmacokinetic data suggest that this intoxication could be due to the intake of capsules containing $5 \mathrm{mg}$ of triiodothyronine, i.e. a dose 200 times higher than that prescribed by her physician.

KEY WORDS: Triiodothyronine. Intoxication. Overdose. Charcoal haemoperfusion. Pharmacokinetics.

Botella de Maglia J, Compte Torrero L, Rivas Sánchez A, Pérez Pastor JL. Intoxicación por triyodotironina. Estudio clínico y farmacocinético. An Med Interna (Madrid) 2003; 20: 627-629.

\section{INTRODUCCIÓN}

Se dispone de limitada información acerca de la sobredosis de hormonas tiroideas en el ser humano. Se han publicado casos de sobredosis de tiroxina (1-9), pero hay poca información sobre la sobredosis de triyodotironina. El interés del caso que presentamos a continuación reside en que se trata, con mucho, de la mayor sobredosis de triyodotironina en el ser humano notificada en la literatura científica hasta la fecha y en que su estudio nos ha permitido: a) conocer la cinética de eliminación de la triyodotironina en los casos de sobredosis masiva; b) evaluar el efecto que sobre ella ha tenido un procedimiento terapéutico (la hemoperfusión con cartucho de carbón activado), y c) proponer un posible mecanismo causal.

\section{CASO APORTADO}

Se trata de una mujer de 42 años, tiroidectomizada un año antes por carcinoma papilar de tiroides y luego sometida a tratamiento de eliminación de restos tiroideos con ${ }^{131} \mathrm{I}$, que seguía tratamiento sustitutivo-supresivo con L-tiroxina. Con objeto de realizar un estudio de extensión para evaluar la eficacia del tratamiento aplicado un año antes, se interrumpió la toma de L-tiroxina durante cinco semanas; y para minimizar los síntomas del hipotiroidismo se le prescribió la toma de cápsulas de $25 \mu \mathrm{g}$ de triyodotironina cada 8 horas durante las tres primeras semanas.

A los nueve días de comenzar este tratamiento, la paciente consultó por dolor abdominal, náuseas, vómitos, fiebre de hasta $40^{\circ} \mathrm{C}$, mareo, malestar general y sensación punzante en el pecho que aumentaba con la respiración. Su médico sospechó que la paciente

Trabajo aceptado: 30 de abril de 2003 
podría haber tomado una dosis de triyodotironina superior a la recomendada. La primera medición de triyodotironina sérica, que se realizó a las 11 horas de la toma de la última cápsula, arrojó un valor de $575,22 \mathrm{nmol} / 1$ (valor normal: 1,1-2,9 nmol/1). La paciente ingresó en la unidad de medicina intensiva. A la sazón estaba vigil pero algo desorientada, muy desasosegada, con rubeosis facial, taquicardia sinusal a 125 latidos/minuto, taquipnea e hipertensión arterial (157/114 mmHg). Otros datos de la exploración inicial fueron: obesidad moderada con estrías cutáneas anacaradas, angiomas en el hipocondrio derecho, zonas de hiperqueratosis en ambos codos, monocitosis del $24 \%$ y fibrinógeno de $6 \mathrm{~g} / \mathrm{l}$.

A lo largo de los diez días siguientes las tres manifestaciones clínicas cardinales fueron: a) delirio con agitación; b) taquicardia sinusal; y c) hipertensión arterial. No se detectaron arritmias distintas de la propia taquicardia sinusal. La temperatura axilar no superó los $38^{\circ} \mathrm{C}$. Al principio tuvo estreñimiento, pero días después presentó diarrea copiosa durante unas horas. Según lo requirió su estado se le administraron dosis variables de diazepam, levomepromazina, propranolol, esmolol, diltiazem, digoxina, nitroglicerina y captopril. Asimismo se le puso tratamiento con hidrocortisona (100 mg cada $8 \mathrm{~h}$ ), colestiramina y cuatro sesiones de hemoperfusión con cartucho de carbón activado. En relación con la hemoperfusión presentó trombopenia y anemia, esta última por coagulación de la sangre en uno de los cartuchos y pérdida sanguínea por una de las vías venosas. Presentó también una infección urinaria por Escherichia coli relacionada con la sonda de Foley, que respondió al tratamiento con amoxicilina/clavulánico.

La triyodotironina sérica regresó a la normalidad a las 200 horas de la última dosis, pero las manifestaciones clínicas citadas tardaron tres días más en desaparecer. Se retiró todo el tratamiento y pasó a una sala de hospitalización. Durante los días siguientes presentó descamación de la piel de las palmas de las manos y plantas de los pies.

Estudio farmacocinético. Se determinó la triyodotironina sérica total mediante inmunoanálisis quimioluminiscente con un autoanalizador Immulite 2000 (Diagnostic Products Corporation, Los Ángeles, EE.UU.), que tiene una sensibilidad de 19 ng/dl. Las concentraciones por encima del límite superior del procedimiento se determinaron tras diluir las muestras con el diluyente recomendado por el fabricante, que consiste en suero humano con valor muy bajo o indetectable de triyodotironina.

Disponemos de una medición sérica a las 11 horas de la ingestión de la última cápsula y de 58 mediciones realizadas durante su estancia en la unidad de medicina intensiva, la mayor parte de ellas a intervalos de 3 horas. Los resultados configuran la curva de eliminación de este fármaco que se muestra en la figura 1.

La cinética de eliminación de la triyodotironina se ajustó a una ecuación de regresión lineal con $\mathrm{R}^{2}$ ajustada $=0,98$, cuya expresión es la siguiente:

Donde:

$$
\log \left[\mathrm{T}_{3}\right]=2,9-0,0122 \mathrm{t}
$$

$\left[\mathrm{T}_{3}\right]$ : concentración de la triyodotironina total en el suero de la paciente, expresada en nmol/l

t: tiempo transcurrido desde la toma de la última cápsula, expresado en $\mathrm{h}$.

En la figura 2 se representa esta ecuación con los límites del intervalo de confianza del $95 \%$.

La vida media de eliminación o tiempo de hemicresis fue de 24 horas y 40 minutos.

El valor de la constante $K$ (en la expresión $y=y_{o} \cdot e^{-\frac{1}{k}}$ ) (10) fue de 35,60 horas. Dicho de otra forma, cada hora se redujo la concentración sérica del fármaco en el $2,77 \%$ de su valor. Ninguna de las cuatro sesiones de hemoperfusión con cartucho de carbón activado fue seguida de una reducción de la concentración sérica de triyodotironina sustancialmente mayor que la que cabía esperar por la propia velocidad de eliminación descrita.

Por extrapolación de estos datos calculamos que la máxima concentración sérica de triyodotironina debió estar en torno a $794,31 \mathrm{nmol} / 1$, con intervalo de confianza del $95 \%$ entre 676,54 y 932,69 nmol/1. Así pues, una concentración sérica 397 veces

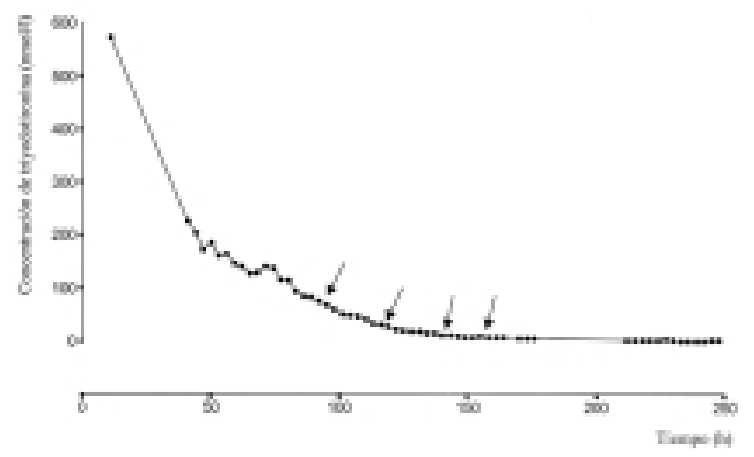

Fig. 1. Disminución de la concentración sérica de triyodotironina total a partir de la toma de la última cápsula. Las flechas indican las cuatro sesiones de hemoperfusión con cartucho de carbón activado.

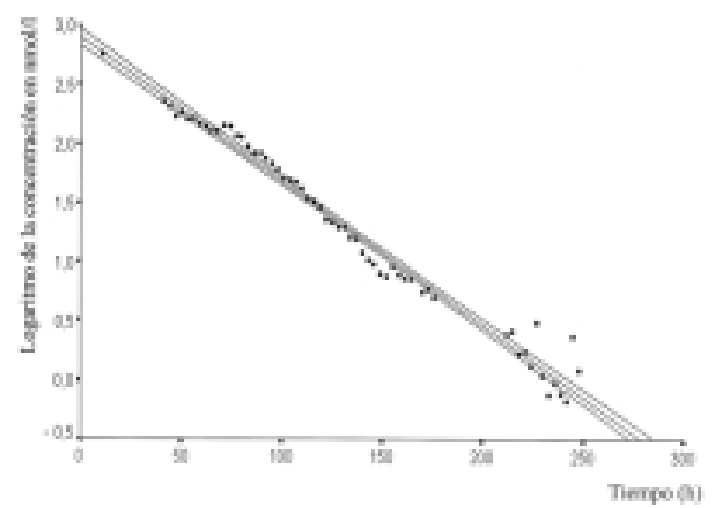

Fig. 2. Disminución del logaritmo de la concentración sérica de triyodotironina total a partir de la toma de la última cápsula. Se representa también la ecuación de regresión lineal que describe este fenómeno (línea central) y los límites del intervalo de confianza del 95\% (a ambos lados).

superior al promedio de normalidad en sujetos sanos ( $2 \mathrm{nmol} / \mathrm{l})$.

Los datos anteriores indican que cada 8 horas se produjo una reducción del $20,13 \%$ de la concentración sérica. Si aceptamos que la cifra de 794,31 nmol/l corresponde a la máxima concentración sérica alcanzable con el régimen posológico que había seguido la paciente (pues llevaba nueve días tomando una cápsula cada 8 horas), concluimos que cada una de las cápsulas contenía suficiente triyodotironina como para incrementar la concentración sérica de esta hormona en $159,86 \mathrm{nmol} / \mathrm{l}$. Puesto que sabemos que el volumen de distribución de la triyodotironina en un ser humano adulto es de 45 litros $(11,12)$ y que por vía oral se absorbe aproximadamente el $95 \%$ de la dosis administrada $(13,14)$, concluimos que cada dosis de triyodotironina debió estar en torno a 4.929,83 $\mu \mathrm{g}$.

A tenor de estos datos farmacocinéticos, los autores creemos que este caso de intoxicación pudo deberse a que las cápsulas que tomó la paciente contuvieran $5 \mathrm{mg}$ de triyodotironina, es decir, una dosis 200 veces superior a la prescrita por su médico.

\section{DISCUSIÓN}

Los datos que pueden obtenerse del estudio de un caso clínico aislado tienen sólo escaso valor a la hora de extraer conclusiones de aplicación general. No obstante, este caso nos permite aportar algunas reflexiones.

Cabe esperar que una concentración sérica de triyodotironina 397 veces superior a la normal puede dar lugar a una "tormenta tiroidea" con manifestaciones clínicas muy graves y potencialmente mortales, tales como arritmias, hipertermia 
o convulsiones. Sin embargo, es digno de consideración el hecho de que tales manifestaciones no se hayan dado en este caso. Las manifestaciones clínicas que presentó la paciente (delirio, agitación, taquicardia e hipertensión arterial) fueron importantes, pero no extremadamente graves. En cualquier caso, pudieron ser tratadas con medicamentos de uso habitual en la unidad de medicina intensiva. Ello sugiere que el pronóstico de la sobredosis por cantidades masivas de triyodotironina, aun siendo siempre grave, podría ser más benigno de lo que a priori cabría pensar, al menos en algunos casos. En cuanto a la persistencia de las manifestaciones clínicas tres días después de la normalización de la triyodotironina sérica, ésta está en consonancia con el hecho de que la vida media biológica de esta hormona (aproximadamente dos días y medio) es netamente superior a su vida media de eliminación.

Los efectos de la sobredosis de hormonas tiroideas se tratan sintomáticamente con medicamentos sedantes y $\beta$ bloqueantes. La dexametasona y el propranolol inhiben la conversión de la tiroxina en triyodotironina, lo cual puede ser útil en la sobredosis de tiroxina, pero no en la de triyodotironina. Adicionalmente, los corticosteroides podrían ser de utilidad para prevenir una posible insuficiencia corticosuprarrenal aguda desencadenada por el aumento de la demanda metabólica (a tal fin se usó en nuestra paciente la hidrocortisona). Obviamente, el propiltiouracilo y otros inhibidores de la síntesis de hormonas tiroideas no están indicados en la sobredosis de triyodotironina ni tienen utilidad alguna en los pacientes tiroprivos. La colestiramina se usa para impedir el círculo enterohepático, ya que una parte de la triyodotironina se excreta por la bilis. En casos de intoxicación por Ltiroxina se han utilizado la plasmaféresis $(2,4,8)$, la exanguinotransfusión (15) y la hemoperfusión con cartucho de carbón activado (4). Se han publicado dos casos en los que la plasmaféresis no resultó ser útil $(2,8)$ y un estudio sobre seis pacientes tratados con plasmaféresis y/o hemoperfusión en el que ambos procedimientos aceleraron considerablemente la eliminación de la tiroxina y de la triyodotironina (4). Nuestro estudio farmacoci-

\section{Bibliografía}

1. Nystrøm E, Lindstedt G, Lundberg PA. Minor signs and symptoms of toxicity in a young woman in spite of massive thyroxine ingestion. Acta Med Scand 1980; 207: 135-136.

2. May ME, Mintz PD, Lowry P, Geller R, Curnow RT. Plasmapheresis in thyroxine overdose: a case report. J Toxicol Clin Toxicol 1983; 20: 517520.

3. Roesch C, Becker PG, Sklar S. Management of a child with acute thyroxine ingestion. Ann Emerg Med 1985; 14: 1.114-1.1155.

4. Binimelis J, Bassas L, Marruecos L, Rodríguez J, Domingo ML, Madoz P, Armengol S, Mangues MA, de Leiva A. Massive thyroxine intoxication: evaluation of plasma extraction. Intensive Care Med 1987;13: 33-38.

5. Golightly LK, Smolinske SC, Kulig KW, Wruk KM, Gelman CJ, Rumack BH, Linden $\mathrm{CH}$. Clinical effects of accidental levothyroxine ingestion in children. Am J Dis Child 1987; 141: 1.025-1.027.

6. Lewander WJ, Lacouture PG, Silva JE, Lovejoy FH. Acute thyroxine ingestion in pediatric patients. Pediatrics 1989; 84: 262-265.

7. Mandel SH, Magnusson AR, Burton BT, Swanson JR, LaFranchi SH. Massive levothyroxine ingestion. Conservative management. Clin Pediatr (Phila) 1989; 28: 374-376.

8. Henderson A, Hickman P, Ward G, Pond SM. Lack of efficacy of plasmapheresis in a patient overdosed with thyroxine. Anaesth Intensive Care 1994; 22: 463-464.

9. Hack JB, Leviss JA, Nelson LS, Hoffman RS. Severe symptoms following a massive intentional L-thyroxine ingestion. Vet Hum Toxicol 1999; 41: 323-326.

10. Laporte JR. Farmacocinética. En: García Valdecasas FG, Laporte J, Sal- nético no ha podido poner de manifiesto ninguna utilidad de la hemoperfusión para reducir apreciablemente los niveles de triyodotironina, y sí, en cambio, efectos indeseables tales como trombopenia y anemia. A la luz de esta experiencia, el desfavorable balance beneficio-riesgo de la hemoperfusión nos lleva a desaconsejar su uso en la intoxicación por triyodotironina.

La farmacocinética de la triyodotironina en el ser humano es conocida desde tiempo ha, pero ignorábamos si sus características serían las mismas en un caso de sobredosis tan extremo como el que presentamos. La vida media de eliminación de 24 horas y 40 minutos que hemos hallado en nuestro estudio es coincidente con la notificada por Nicoloff y cols. (25 horas) (16). Otros autores $(11,17,18)$ han publicado cifras entre 16 y 49 horas.

Nuestro estudio nos ha llevado a concluir que este caso de intoxicación es compatible con la posibilidad de que durante nueve días la paciente hubiera estado tomando cápsulas con 5 mg de triyodotironina cada 8 horas. Ello podría deberse a un error durante la preparación de la fórmula magistral. Otras explicaciones son posibles pero nos parecen menos probables. Por ejemplo, la intoxicación podría haberse producido por la toma de un número elevado de cápsulas de $25 \mu \mathrm{g}$, pero para elevar la concentración de triyodotironina sérica hasta 794,31 nmol/l habría sido menester que la paciente hubiera ingerido 978 cápsulas, cifra muy superior al número de que disponía.

La posibilidad de que se produzca algún error durante la preparación de la fórmula magistral (por ejemplo, confundir microgramos con miligramos) no es remota, porque este medicamento se prescribe con poca frecuencia y algunos farmacéuticos podrían no estar familiarizados con las dosis habituales. Esta posibilidad añade cierto riesgo al tratamiento con triyodotironina en fórmula magistral y deja el camino abierto a un debate sobre la conveniencia o inconveniencia de usar este medicamento para minimizar temporalmente los síntomas de hipotiroidismo en los pacientes tiroprivos a los que se interrumpe el tratamiento con L-tiroxina. vá JA, Cuenca E, Esplugues J, Bartolomé M, Forn J, Jané F, Brugger A, Erill S, Rodríguez L. Bases farmacológicas de la terapéutica medicamentosa. Salvat, Barcelona 1969; 81-95.

11. Woeber KA, Sobel RJ, Ingbar SH, Sterling K. The peripheral metabolism of triiodothyronine in normal subjects and in patients with hyperthyroidism. J Clin Invest 1970; 49: 643-649.

12. Woeber KA, Hecker E, Ingbar SH. The effects of an acute load of thyroxine on the transport and peripheral metabolism of triiodothyronine in man. J Clin Invest 1970; 49: 650-654.

13. Hays MT. Absorption of triiodothyronine in man. J Clin Endocrinol Metab 1970; 30: 675-676.

14. Surks MI, Schadlow AR, Stock JM, Oppenheimer JH. Determination of iodothyronine absorption and conversion of L-thyroxine (T4) to L-triiodothyronine (T3) using turnover rate techniques. J Clin Invest 1973; 52: 805-811.

15. Gerard P, Malvaux P, De Visscher M. Accidental poisoning with thyroid extract treated by exchange transfusion. Arch Dis Child 1972;47:981-982

16. Nicoloff JT, Low JC, Dussault JH, Fisher DA. Simultaneous measurement of thyroxine and triiodotyronine peripheral turnover kinetics in man. J Clin Invest 1972; 51: 473-483.

17. Cavalieri RR, Steinberg M, Searle GL. Metabolic clearance rate of 1triiodotironine in man: a comparison of results by single-injection and constant infusion methods. J Clin Endocrinol Metab 1971; 33: 624.

18. Oddie TH, Fisher DA, Dussault JH, Thompson CS. Triiodothyronine turnover in euthyroid subjects. J Clin Endocrinol Metab 1971; 33: 653-660. 